\title{
ENERGI TOTAL KEADAAN DASAR ATOM BERILIUM DENGAN TEORI GANGGUAN
}

\author{
LIU KIN MEN *1, SETIANTO $^{1}$, BAMBANG M. WIBAWA ${ }^{2}$ \\ ${ }^{1}$ Departemen Fisika Fakultas MIPA Universitas Padjadjaran, \\ Jl. Raya Bandung-Sumedang Km 21, Jatinangor 45363 \\ ${ }^{2}$ Departemen Teknik Elektro Fakultas MIPA Universitas Padjadjaran, \\ Jl. Raya Bandung-Sumedang Km 21, Jatinangor 45363 \\ *email :liu@phys.unpad.ac.id
}

\begin{abstract}
Abstrak. Atom Berilium adalah suatu atom yang mempunyai 4 buah elektron pada kulitnya. Pada keadaan dasar, dua elektron menduduki orbital 1s dan dua elektron lainnya menduduki orbital 2s. Fungsi gelombang total keadaan dasar ditentukan berdasarkan determinan Slater. Hamiltonian total merupakan gabungan dari Hamiltonian masingmasing elektron dan suku interaksi di antara keempat elektron bersangkutan. Dengan diperolehnya fungsi gelombang total dan Hamiltonian total, maka energi total keadaan dasar atom Berilium dapat ditentukan. Perhitungan dilakukan dengan teori gangguan dan diperoleh $E_{0}=-363,75 \mathrm{eV}$.
\end{abstract}

Kata kunci : Atom Berilium, keadaan dasar, teori gangguan

\begin{abstract}
Beryllium atom is an atom that has four electrons in the shell. In the ground state, two electrons occupy the 1 s orbital and two other electrons occupy the $2 \mathrm{~s}$ orbital. The ground state total wave function is determined by the Slater determinant. The total Hamiltonian is a combination of each electron Hamiltonian and interaction term between the four electrons. By obtaining the total wave function and total Hamiltonian, then the ground state total energy of Beryllium atom can be determined. The calculation performed by perturbation theory and obtained $E_{0}=-363,75 \mathrm{eV}$.
\end{abstract}

Keywords : Beryllium atom, ground state, perturbation theory

\section{Pendahuluan}

Dalam teori kuantum atom Hidrogen yaitu suatu atom yang hanya mempunyai satu elektron pada kulitnya, melalui persamaan Schrodinger diperoleh fungsi-fungsi gelombang (orbital-orbital) elektron dan energi-energi yang bersangkutan [1,2]. Hasil-hasil ini selanjutnya dipergunakan sebagai basis untuk menggambarkan atom-atom dengan sejumlah elektron, khususnya berkaitan dengan energi total keadaan dasar dan energi total keadaan eksitasi [3]. Untuk energi total keadaan dasar, penentuan telah dilakukan pada atom Litium [4] dan atom Berilium [5]. Di sisi lain untuk energi total keadaan eksitasi, penentuan telah dilakukan pada atom Litium [6]. Semua penentuan ini dilakukan dengan metode variasi. Cara lain yang perhitungannya lebih sederhana adalah dengan teori gangguan. Untuk itu dalam kajian ini dilakukan perhitungan energi total keadaan dasar atom Berilium dengan teori gangguan. 
Tingkat-tingkat energi dan fungsi-fungsi gelombang atom Berilium tidak diperoleh secara langsung melalui persamaan Schrodinger. Tingkat-tingkat energi dan fungsifungsi gelombang ini didasarkan pada atom Hidrogen ( biasanya dikenal sebagai mirip-Hidrogen ). Berilium adalah suatu contoh dari atom-atom dengan banyak elektron.

\section{Metode Penelitian}

Fungsi gelombang total keadaan dasar dari atom dengan banyak elektron ( Nelektron ) diungkapkan oleh determinan Slater yaitu:

$\Psi_{0}=\frac{1}{\sqrt{N !}}\left|\begin{array}{cccc}\varphi_{1}(1) \alpha(1) & \varphi_{1}(1) \beta(1) & \ldots & \varphi_{N / 2}(1) \beta(1) \\ \varphi_{1}(2) \alpha(2) & \varphi_{1}(2) \beta(2) & \ldots & \varphi_{N / 2}(2) \beta(2) \\ \ldots & \ldots & \ldots & \ldots \\ \varphi_{1}(N) \alpha(N) & \varphi_{1}(N) \beta(N) & \ldots & \varphi_{N / 2}(N) \beta(N)\end{array}\right|$,

sedangkan Hamiltonian totalnya adalah:

$\widehat{H}=\sum_{i}\left(H_{i}+\frac{1}{2} \sum_{j \neq i} \frac{e^{2}}{4 \pi \epsilon_{0} r_{i j}}\right)$.

Dalam hal ini $\varphi_{1}(1) \alpha(1)$ menyatakan orbital 1 yang diduduki oleh elekron 1 dan mempunyai spin $\alpha$, dan dengan cara yang sama berarti suku yang terakhir $\varphi_{N / 2}(N) \beta(N)$ menyatakan orbital $\mathrm{N} / 2$ yang diduduki oleh elektron $\mathrm{N}$ dan mempunyai spin $\beta$. Selanjutnya $e$ adalah muatan elektron, $\epsilon_{0}$ adalah permitivitas ruang hampa, $r_{i j}$ adalah jarak antara elektron $\mathrm{ke}-i$ dan elektron ke $-j$, karena itu suku kedua sebelah kanan dari persamaan adalah potensial interaksi di antara elektron-elektron, dan:

$H_{i}=-\frac{\hbar^{2}}{2 m} \nabla_{i}^{2}-\frac{Z e^{2}}{4 \pi \epsilon_{0} r_{i}}$

adalah Hamiltonian dari elektron tunggal.

Untuk Berilium pada keadaan dasar ( terdiri dari 4 buah elektron, 2 elektron menduduki orbital $1 \mathrm{~s}$ dan 2 elektron menduduki orbital $2 \mathrm{~s}$ ), fungsi gelombang totalnya adalah:

$\Psi_{0}=\frac{1}{\sqrt{24}}\left|\begin{array}{llll}\varphi_{1 s}(1) \alpha(1) & \varphi_{1 s}(1) \beta(1) & \varphi_{2 s}(1) \alpha(1) & \varphi_{2 s}(1) \beta(1) \\ \varphi_{1 s}(2) \alpha(2) & \varphi_{1 s}(2) \beta(2) & \varphi_{2 s}(2) \alpha(2) & \varphi_{2 s}(2) \beta(2) \\ \varphi_{1 s}(3) \alpha(3) & \varphi_{1 s}(3) \beta(3) & \varphi_{2 s}(3) \alpha(3) & \varphi_{2 s}(3) \beta(3) \\ \varphi_{1 s}(4) \alpha(4) & \varphi_{1 s}(4) \beta(4) & \varphi_{2 s}(4) \alpha(4) & \varphi_{2 s}(4) \beta(4)\end{array}\right|$,

sedangkan Hamiltonian totalnya adalah:

$\widehat{H}=H_{1}+H_{2}+H_{3}+H_{4}+\frac{e^{2}}{4 \pi \epsilon_{0} r_{12}}+\frac{e^{2}}{4 \pi \epsilon_{0} r_{13}}+\frac{e^{2}}{4 \pi \epsilon_{0} r_{14}}+\frac{e^{2}}{4 \pi \epsilon_{0} r_{23}}+\frac{e^{2}}{4 \pi \epsilon_{0} r_{24}}+$ $\frac{e^{2}}{4 \pi \epsilon_{0} r_{34}}$.

Dalam teori gangguan, energi total keadaan dasar ditentukan berdasarkan hubungan: 
$E_{0}=<\Psi_{0}|\widehat{H}| \Psi_{0}>$,

dalam hal ini $\Psi_{0}$ adalah fungsi gelombang total keadaan dasar dan $\widehat{H}$ adalah Hamiltonian total dari sistem yang bersangkutan. Di sini $\Psi_{0}$ dan $\widehat{H}$ mengandung parameter $Z$ yang nilainya diambil sama dengan 4 yaitu nomor atom dari atom Berilium.

\section{Hasil dan Pembahasan}

Berdasarkan fungsi gelombang total dan Hamiltonian total yang telah dituliskan pada bagian sebelumnya, diperoleh energi total keadaan dasar atom Berilium adalah:

$E_{0}=2 E_{1 s}+2 E_{2 s}+J_{11}+4 J_{12}+J_{22}-2 K_{12}$,

dalam hal ini

$$
\begin{aligned}
E_{1 s} & =<\varphi_{1 s}(1)\left|H_{1}\right| \varphi_{1 s}(1)>=<\varphi_{1 s}(2)\left|H_{2}\right| \varphi_{1 s}(2)>=<\varphi_{1 s}(3)\left|H_{3}\right| \varphi_{1 s}(3)> \\
& =<\varphi_{1 s}(4)\left|H_{4}\right| \varphi_{1 s}(4)> \\
E_{2 s} & =<\varphi_{2 s}(1)\left|H_{1}\right| \varphi_{2 s}(1)>=<\varphi_{2 s}(2)\left|H_{2}\right| \varphi_{2 s}(2)>=<\varphi_{2 s}(3)\left|H_{3}\right| \varphi_{2 s}(3)> \\
& =<\varphi_{2 s}(4)\left|H_{4}\right| \varphi_{2 s}(4)> \\
J_{11} & =<\varphi_{1 s}(1) \varphi_{1 s}(2)\left|\frac{e^{2}}{4 \pi \epsilon_{0} r_{12}}\right| \varphi_{1 s}(1) \varphi_{1 s}(2)> \\
& =<\varphi_{1 s}(1) \varphi_{1 s}(3)\left|\frac{e^{2}}{4 \pi \epsilon_{0} r_{13}}\right| \varphi_{1 s}(1) \varphi_{1 s}(3)> \\
& =<\varphi_{1 s}(1) \varphi_{1 s}(4)\left|\frac{e^{2}}{4 \pi \epsilon_{0} r_{14}}\right| \varphi_{1 s}(1) \varphi_{1 s}(4)> \\
& =<\varphi_{1 s}(2) \varphi_{1 s}(3)\left|\frac{e^{2}}{4 \pi \epsilon_{0} r_{23}}\right| \varphi_{1 s}(2) \varphi_{1 s}(3)> \\
= & <\varphi_{1 s}(1) \varphi_{2 s}(3)\left|\frac{e^{2}}{4 \pi \epsilon_{0} r_{13}}\right| \varphi_{1 s}(1) \varphi_{2 s}(3)> \\
= & <\varphi_{1 s}(2) \varphi_{1 s}(4)\left|\frac{e^{2}}{4 \pi \epsilon_{0} r_{24}}\right| \varphi_{1 s}(2) \varphi_{1 s}(4)> \\
= & <\varphi_{1 s}(3) \varphi_{1 s}(4)\left|\frac{e^{2}}{4 \pi \epsilon_{0} r_{34}}\right| \varphi_{1 s}(3) \varphi_{1 s}(4)> \\
J_{12}= & <\varphi_{1 s}(1) \varphi_{2 s}(2)\left|\frac{e^{2}}{4 \pi \epsilon_{0} r_{12}}\right| \varphi_{1 s}(1) \varphi_{2 s}(2)> \\
&
\end{aligned}
$$




$$
\begin{aligned}
& =<\varphi_{1 s}(1) \varphi_{2 s}(4)\left|\frac{e^{2}}{4 \pi \epsilon_{0} r_{14}}\right| \varphi_{1 s}(1) \varphi_{2 s}(4)> \\
& =<\varphi_{1 s}(2) \varphi_{2 s}(3)\left|\frac{e^{2}}{4 \pi \epsilon_{0} r_{23}}\right| \varphi_{1 s}(2) \varphi_{2 s}(3)> \\
& =<\varphi_{1 s}(2) \varphi_{2 s}(4)\left|\frac{e^{2}}{4 \pi \epsilon_{0} r_{24}}\right| \varphi_{1 s}(2) \varphi_{2 s}(4)> \\
& =<\varphi_{1 s}(3) \varphi_{2 s}(4)\left|\frac{e^{2}}{4 \pi \epsilon_{0} r_{34}}\right| \varphi_{1 s}(3) \varphi_{2 s}(4)> \\
& J_{22}=<\varphi_{2 s}(1) \varphi_{2 s}(2)\left|\frac{e^{2}}{4 \pi \epsilon_{0} r_{12}}\right| \varphi_{2 s}(1) \varphi_{2 s}(2)> \\
& =<\varphi_{2 s}(1) \varphi_{2 s}(3)\left|\frac{e^{2}}{4 \pi \epsilon_{0} r_{13}}\right| \varphi_{2 s}(1) \varphi_{2 s}(3)> \\
& =<\varphi_{2 s}(1) \varphi_{2 s}(4)\left|\frac{e^{2}}{4 \pi \epsilon_{0} r_{14}}\right| \varphi_{2 s}(1) \varphi_{2 s}(4)> \\
& =<\varphi_{2 s}(2) \varphi_{2 s}(3)\left|\frac{e^{2}}{4 \pi \epsilon_{0} r_{23}}\right| \varphi_{2 s}(2) \varphi_{2 s}(3)> \\
& =<\varphi_{2 s}(2) \varphi_{2 s}(4)\left|\frac{e^{2}}{4 \pi \epsilon_{0} r_{24}}\right| \varphi_{2 s}(2) \varphi_{2 s}(4)> \\
& =<\varphi_{2 s}(3) \varphi_{2 s}(4)\left|\frac{e^{2}}{4 \pi \epsilon_{0} r_{34}}\right| \varphi_{2 s}(3) \varphi_{2 s}(4)>
\end{aligned}
$$

Dan

$$
\begin{aligned}
K_{12} & =<\varphi_{1 s}(1) \varphi_{2 s}(2)\left|\frac{e^{2}}{4 \pi \epsilon_{0} r_{12}}\right| \varphi_{2 s}(1) \varphi_{1 s}(2)> \\
& =<\varphi_{1 s}(1) \varphi_{2 s}(3)\left|\frac{e^{2}}{4 \pi \epsilon_{0} r_{13}}\right| \varphi_{2 s}(1) \varphi_{1 s}(3)> \\
& =<\varphi_{1 s}(1) \varphi_{2 s}(4)\left|\frac{e^{2}}{4 \pi \epsilon_{0} r_{14}}\right| \varphi_{2 s}(1) \varphi_{1 s}(4)> \\
& =<\varphi_{1 s}(2) \varphi_{2 s}(3)\left|\frac{e^{2}}{4 \pi \epsilon_{0} r_{23}}\right| \varphi_{2 s}(2) \varphi_{1 s}(3)> \\
& =<\varphi_{1 s}(2) \varphi_{2 s}(4)\left|\frac{e^{2}}{4 \pi \epsilon_{0} r_{24}}\right| \varphi_{2 s}(2) \varphi_{1 s}(4)>
\end{aligned}
$$




$$
=<\varphi_{1 s}(3) \varphi_{2 s}(4)\left|\frac{e^{2}}{4 \pi \epsilon_{0} r_{34}}\right| \varphi_{2 s}(3) \varphi_{1 s}(4)>\text {. }
$$

Dengan substitusi orbital-orbital 1s dan 2s dari atom Berilium:

$$
\begin{aligned}
& \varphi_{1 s}=\frac{1}{\sqrt{\pi}}\left(\frac{4}{a_{0}}\right)^{\frac{3}{2}} e^{-4 r} / a_{0} \\
& \varphi_{2 s}=\frac{1}{4 \sqrt{2 \pi}}\left(\frac{4}{a_{0}}\right)^{\frac{3}{2}}\left(2-\frac{4 r}{a_{0}}\right) e^{-2 r / a_{0}},
\end{aligned}
$$

diperoleh:

$$
\begin{aligned}
& E_{1 s}=-\frac{e^{2}}{8 \pi \epsilon_{0} a_{0}}(4)^{2}=-217,6 \mathrm{eV} \\
& E_{2 s}=-\frac{e^{2}}{8 \pi \epsilon_{0} a_{0}} \frac{(4)^{2}}{(2)^{2}}=-54,4 \mathrm{eV} \\
& J_{11}=-\frac{e^{2}}{8 \pi \epsilon_{0} a_{0}}\left(-\frac{5}{4}\right)(4)=68 \mathrm{eV} \\
& J_{12}=-\frac{e^{2}}{4 \pi \epsilon_{0} a_{0}}\left(-\frac{17}{81}\right)(4)=22,83 \mathrm{eV} \\
& J_{22}=-\frac{e^{2}}{4 \pi \epsilon_{0} a_{0}}\left(-\frac{121}{512}\right)(4)=25,71 \mathrm{eV}
\end{aligned}
$$

dan:

$$
K_{12}=-\frac{e^{2}}{4 \pi \epsilon_{0} a_{0}}\left(-\frac{16}{729}\right)(4)=2,39 \mathrm{eV} .
$$

Karena itu energi total keadaan dasar atom Berilium dengan teori gangguan adalah:

$$
E_{0}=-363,75 \mathrm{eV} \text {. }
$$

\section{Kesimpulan}

Telah dilakukan perhitungan energi total keadaan dasar atom Berilium dengan teori gangguan dan diperoleh $E_{0}=-363,75 \mathrm{eV}$. Suku interaksi antar elektron memberikan kontribusi yang cukup besar bagi energi total. Pengambilan nilai $Z=$ 4 membuat hasil perhitungan energi total sedikit bergeser dari nilai yang diharapkan.

\section{Ucapan terima kasih}

Penulis menyampaikan terima kasih kepada Haeruman, Heri Sembiring, Muhammad Rizqan Akbar, dan Apollos Theophilus Silitonga atas diskusi-diskusi berkaitan dengan topik yang dikaji. Terima kasih juga disampaikan kepada Kosam Erawan dan Anda Suhanda atas dukungan-dukungan yang diberikan dalam Penyelesaian tulisan ini 


\section{Daftar Pustaka}

1. R.E Siregar, Fisika Kuantum, Widya Padjadjaran (2010).

2. S. Gasiorowicz, Quantum Physics, John Wiley and Sons (2003).

3. R. E. Siregar, Struktur Elektronik Atom dan Molekul, Diktat (2014).

4. L. K. Men, Energi Total Keadaan Dasar Atom Litium dengan Metode Variasi, Laporan Penelitian Mandiri, Tidak Dipublikasikan (2014).

5. L. K. Men, Energi Total Keadaan Dasar Atom Berilium dengan Metode Variasi, Laporan Penelitian Mandiri, Tidak Dipublikasikan (2016).

6. L. K. Men, Setianto, Energi Total Keadaan Eksitasi Atom Litium dengan Metode Variasi, Jurnal Ilmu dan Inovasi Fisika, Vol. 01 No. 01 (2017) p. 6-10. 